\title{
Corrigendum: Flux balance analysis reveals acetate metabolism modulates cyclic electron flow and alternative glycolytic pathways in Chlamydomonas reinhardtii
}

\author{
Stephen P. Chapman, Caroline M. Paget, Giles N. Johnson and Jean-Marc Schwartz * \\ Faculty of Life Sciences, University of Manchester, Manchester, UK
}

Keywords: glycolysis, mixotrophic growth, metabolic model, photosynthesis, green algae, flux balance analysis, acetate metabolism, cyclic electron flow

\section{A corrigendum on}

Flux balance analysis reveals acetate metabolism modulates cyclic electron flow and alternative glycolytic pathways in Chlamydomonas reinhardtii

OPEN ACCESS

Edited and reviewed by: Zoran Nikoloski,

Max-Planck Institute of Molecular

Plant Physiology, Germany

${ }^{*}$ Correspondence:

Jean-Marc Schwartz

jean-marc.schwartz@

manchester.ac.uk

Specialty section:

This article was submitted to Plant Systems and Synthetic Biology,

a section of the journal

Frontiers in Plant Science

Received: 25 February 2016

Accepted: 08 March 2016

Published: 22 March 2016

Citation:

Chapman SP, Paget CM, Johnson GN and Schwartz J-M (2016)

Corrigendum: Flux balance analysis reveals acetate metabolism modulates

cyclic electron flow and alternative

glycolytic pathways in

Chlamydomonas reinhardtii.

Front. Plant Sci. 7:362.

doi: 10.3389/fpls.2016.00362 by Chapman, S. P., Paget, C. M., Johnson, G. N., and Schwartz, J.-M. (2015). Front. Plant Sci. 6:474. doi: $10.3389 / f p l s .2015 .00474$

Reason for Corrigendum:

There was a mistake with the naming of the genome-scale metabolic model of Chlamydomonas reinhardtii originally published in Molecular Systems Biology in 2011 (Chang et al., 2011). In our article there are 10 instances where we refer to the model as iCR1080, however the correct name should be $i \mathrm{RC1080}$, named after the initials of the researcher who reconstructed it. The authors apologize for the mistake. This error does not affect the scientific conclusions of the article in any way.

\section{AUTHOR CONTRIBUTIONS}

All authors listed have made substantial, direct and intellectual contribution to the work, and approved it for publication.

\section{REFERENCES}

Chang, R. L., Ghamsari, L., Manichaikul, A., Hom, E. F., Balaji, S., Fu, W., et al. (2011). Metabolic network reconstruction of Chlamydomonas offers insight into light-driven algal metabolism. Mol. Syst. Biol. 7, 52. doi: 10.1038/msb.2011.52

Conflict of Interest Statement: The authors declare that the research was conducted in the absence of any commercial or financial relationships that could be construed as a potential conflict of interest.

Copyright $\odot 2016$ Chapman, Paget, Johnson and Schwartz. This is an open-access article distributed under the terms of the Creative Commons Attribution License (CC BY). The use, distribution or reproduction in other forums is permitted, provided the original author(s) or licensor are credited and that the original publication in this journal is cited, in accordance with accepted academic practice. No use, distribution or reproduction is permitted which does not comply with these terms. 